\title{
Erratum to: Removal of Muscle Artifacts from EEG Recordings of Spoken Language Production
}

\author{
Maarten De Vos • Stephanie Riès • Katrien Vanderperren • Bart Vanrumste • \\ Francois-Xavier Alario • Sabine Van Huffel • Boris Burle
}

Published online: 9 June 2010

(C) Springer Science+Business Media, LLC 2010

Erratum to: Neuroinform (2010) 8: 135-150

DOI 10.1007/s12021-010-9071-0

Due to a production error the names of Maarten De Vos and Sabine Van Huffel were presented incorrectly. We apologize for the error.

The online version of the original article can be found at doi:http://dx. doi.org/10.1007/s12021-010-9071-0.

M. De Vos $(\bowtie) \cdot K$. Vanderperren $\cdot$ B. Vanrumste $\cdot$ S. Van Huffel

Department of Electrical Engineering (ESAT),

Katholieke Universiteit Leuven,

Leuven, Belgium

e-mail: maarten.devos@gmail.com

S. Riès $\cdot$ F.-X. Alario

Laboratoire de Psychologie Cognitive,

Aix-Marseille Université, CNRS,

Marseille, France

S. Riès · B. Burle

Laboratoire de Neurobiologie de la Cognition,

Aix-Marseille Université, CNRS,

Marseille, France

B. Vanrumste

MOBILAB, Katholieke Hogeschool Kempen,

Geel, Belgium 